\title{
Association between urinary incontinence and bone health in Korean elderly women based on data from the Korea National Health and Nutrition Examination Survey
}

\author{
Ji Hyun Moon ${ }^{1}$ Y Yun Hwan Oh${ }^{2}$, Mi Hee Kong ${ }^{1}$, Jung Sik Huh', Hyeon Ju Kim
}

\begin{abstract}
Background: Urinary incontinence and impaired bone health are significant health problems among the elderly. We evaluated the impact of urinary incontinence on bone health in the elderly.

Material and Methods: Our study used data from the Korea National Health and Nutrition Examination. We included 901 women aged $\geq 65$ years. The bone mineral density was measured by dual-energy X-ray absorptiometry. Impaired bone health was characterized by lumbar spine, femoral neck, or total femur T-scores of $\leq-1.0 \mathrm{SD}$. Each participant's incontinence status was recorded using constructed questionnaires.

Results: The prevalence of self-reported urinary incontinence in the women aged $\geq 65$ years was $9.5 \%$. After adjustments for age, height, and weight, the T-scores for the lumbar spine of the urinary incontinence and the no urinary continence groups were $-2.48 \pm 0.11$ and $-2.37 \pm 0.03$, respectively and didn't show the difference between them $(p=0.390)$. Likewise, the T-scores for the total femur and femoral neck were not significantly different. After adjusting for covariates, we found no statistically significant association between impaired bone health with urinary incontinence. Conclusions: This study found urinary incontinence was not an independent risk factor of impaired bone health in the elderly women.
\end{abstract}

Keywords: aged, bone density, urinary incontinence, epidemiologic study

\section{INTRODUCTION}

The International Continence Society defines urinary incontinence as "the complaint of any involuntary leakage of urine" (1). Types of urinary incontinence include urge incontinence, stress incontinence, overflow incontinence, functional incontinence and mixed incontinence. Urinary incontinence, especially stress incontinence, occurs when the pelvic floor muscle weakens and the urethral sphincter malfunctions (2). Thus, pelvic floor muscle exercise such as Kegel exercise improves symptoms and can be considered as a first choice of treatment for elderly women (3). A previous study assessed pelvic architecture and pelvic muscle by using computed tomography in patients with urinary incontinence, as aging is associated with reduced general muscle mass and pelvic muscle. Furthermore, the authors thought that atrophy and decreased pelvic floor muscle (especially the transverse perineal muscle) may disrupt the pelvic architecture angle resulting in urinary incontinence easily (4). According to the current research, increased fat mass which was accurately measured by dual-energy $X$-ray absorptiometry is closely linked to urinary incontinence (5). Change in body composition like as the muscle mass diminished and fat mass increased simultaneously is a common phenomenon in the elderly and it is called sarcopenic obesity (6).

Muscles and bones are closely related to the growth, development, and aging processes of organs. Muscle mechanical stimulation has been believed to be the most important factor of bone growth (7). A previous observational study reports that fat-free mass evaluated using dual-energy $\mathrm{X}$-ray absorptiometry and quadriceps strength are closely related with bone mineral density (BMD) in elderly women (8). However, independent of the mechanical stimulation of the muscles, the evidence suggests that the muscle itself plays a positive role in bone formation and recovery (9). Insulin-like growth factor 1 (IGF-1) and basic fibroblast growth factor 2 (FGF-2) are secreted from the muscles by resistance exercise and

\footnotetext{
Department of Family Medicine Jeju National University \& Hospital, South Korea.

2 Department of Family Medicine Jeju National University Hospital, South Korea.

3 Department of Urology, Jeju National University \& Hospital, South Korea.
}

Correspondence: Hyeon Ju Kim

Received: 1 Aug 2018, Accepted: 5 Nov 2018

Department of Family Medicine Jeju National University \& Hospital, South Korea

E-mail:fmhjukim@hanmail.net

(C) 2019 by the authors; licensee Modestum Ltd., UK. This article is an open access article distributed under the terms and conditions of the Creative Commons Attribution License (http://creativecommons.org/licenses/by/4.0/).

Electronic Journal of General Medicine 
eccentric muscle contraction to stimulate bone formation $(10,11)$. Myostatin is known to inhibit cartilage formation and restoration of fracture during muscle injury or atrophy (9). Muscles and bones interact through these various mechanisms.

Elderly women with urinary incontinence are significantly limited in their activities, which play an important role in maintaining bone health due to frequency and urge sensation (12). Moreover, women with stress-related urinary incontinence had a decreased ability to maintain balance (13), and the urge associated with incontinence increased the risk of fall and non-traumatic fracture in elderly women (14).

On the basis of a previous study, elderly women with impaired bone health were more likely to show muscle loss followed by urinary incontinence. Moreover, women with urinary incontinence may have increased risk of decreased BMD and fall. This study aimed to evaluate the urinary incontinence status of Korean elderly women and to determine the relationship between urinary incontinence, a consequence of muscle loss and impaired bone health, taking into account potential confounding factors.

\section{MATERIALS AND METHODS}

\section{Subjects}

Our study used 18 months data from the Korea National Health and Nutrition Examination Survey (KNHANES; July 2008 to December 2009), supported by the Ministry of Health and Welfare and Korea Centers for Disease Control and Prevention. The KNHANES is a cross-sectional, nationwide survey to monitor the general health status, health behaviors, and nutrition of the Korean population. Similar to the National Health and Nutrition Examination Survey in the United States, each KNHANES uses a multistage sampling design to select participants from the general population of Korea.

The pathogenesis of urinary incontinence differs between men and women. Furthermore, during the research period, among 9,213 men, only $0.5 \%$ claimed to have symptoms of incontinence, and $0.3 \%$ were diagnosed by a physician as having urinary incontinence. For these reasons, we excluded men in this study and included only women aged $\geq 65$ years. We also excluded women with diseases that could affect their BMD, such as myocardiac infarction, stroke, any malignancy, rheumatic arthritis, asthma, or osteoporosis on medication. On the basis of these criteria, 901 women were enrolled in our study.

Each participant provided informed consent prior to inclusion in the study, which was approved by the institutional review board of the Korea Centers for Disease Control and Prevention (2010-02CON-21-C).

\section{Bone Health}

The BMDs $\left(\mathrm{g} / \mathrm{cm}^{2}\right)$ of the lumbar spine $(\mathrm{L} 1-\mathrm{L} 4)$, left femur neck, and total femur were measured with standardized protocols by highly skilled surveyors by using dual-energy X-ray absorptiometry (DISCOVERY W fan-beam densitometer, Hologic Inc., USA). When the left femur bone density was not measurable, the right femur was measured. When both femoral lesions could not be measured, only the lumbar spine BMD was measured. Due to lack of Korean representative bone density data, which are required for calculating the T-score, were available, Japanese BMD reference values were used. Impaired bone health was characterized by a lumbar spine, femoral neck, or total femur T-score of $\leq-1.0$ SD. Subjects who had foreign bodies in bones, underwent femur surgery, had a fracture, or had a deformity were excluded from the analysis.

\section{Urinary Incontinence}

Each participant's incontinence status was determined using questionnaires administered by trained interviewers during face-to-face interviews. Urinary incontinence was determined on the basis of the responses to the questions, "Do you currently have symptoms of urinary incontinence?" and "Have you been diagnosed as having urinary incontinence by a physician?" To these questions, the participants answered "yes" or "no."

\section{Anthropometric Parameters}

The KNHANES consists of self-reported questionnaires, physical measurement, and a nutrition survey. Personal health behaviors such as smoking status, drinking alcohol, physical activities were assessed using self-reported questionnaires. Furthermore chronic disease like hypertension, diabetes, and depression were interviewed. Body measurements such as height and weight were collected by a trained nurse. 
Table 1: Baseline characteristics of study subjects by presence or absence of urinary incontinence

\begin{tabular}{|c|c|c|c|}
\hline & $\begin{array}{c}\text { No Urinary incontinence } \\
\left(\mathrm{N}^{*}=823\right)\end{array}$ & $\begin{array}{c}\text { Urinary incontinence } \\
\left(\mathbf{N}^{*}=78\right)\end{array}$ & $p$ \\
\hline Age & $73.31 \pm 0.26$ & $74.49 \pm 1.01$ & 0.283 \\
\hline Height $(\mathrm{cm})$ & $150.39 \pm 0.27$ & $151.50 \pm 0.91$ & 0.236 \\
\hline Weight (kg) & $54.07 \pm 0.35$ & $55.97 \pm 1.15$ & 0.120 \\
\hline Body mass index $\left(\mathrm{kg} / \mathrm{m}^{2}\right)$ & $23.87 \pm 0.13$ & $24.32 \pm 0.36$ & 0.247 \\
\hline $25-\mathrm{OH}$ vitamin $\mathrm{D}(\mathrm{ng} / \mathrm{mL})$ & $18.60 \pm 0.38$ & $20.26 \pm 1.32$ & 0.204 \\
\hline Calcium consumption $(\mathrm{mg})$ & $368.31 \pm 31.09$ & $301.16 \pm 28.56$ & 0.113 \\
\hline Physical activity restriction & $59.0(2.2)$ & $43.8(7.3)$ & 0.034 \\
\hline Hypertension & $48.2(2.1)$ & $51.5(7.6)$ & 0.677 \\
\hline Diabetes & $14.4(1.3)$ & $14.0(4.1)$ & 0.933 \\
\hline Depression & $10.4(1.3)$ & $11.8(3.5)$ & 0.699 \\
\hline Hormone replace therapy & $5.1(0.9)$ & $0.6(0.7)$ & 0.015 \\
\hline Smoker & $14.6(1.7)$ & $10.1(3.7)$ & 0.337 \\
\hline Alcohol consumption & & & 0.322 \\
\hline None & $69.0(2.1)$ & $68.2(6.5)$ & \\
\hline Once a week or less frequent & $25.2(2.0)$ & $29.8(6.5)$ & \\
\hline More than twice a week & $5.8(0.9)$ & $1.9(1.3)$ & \\
\hline Exercise frequency & & & 0.328 \\
\hline None & $71.1(1.9)$ & $63.1(7.0)$ & \\
\hline Less than two times a week & $8.0(1.1)$ & $7.8(3.3)$ & \\
\hline Three times a week or more & $20.9(1.6)$ & $29.1(6.3)$ & \\
\hline
\end{tabular}

${ }^{*}$ Unweighted number

Values are expressed as mean \pm standard error, estimated \% (standard error).

Calculated by complex sample general linear model and complex sample logistic regression analysis

\section{Statistical Analysis}

Differences in characteristics between the urinary incontinence and control groups were assessed using the complex sample logistic regression analysis for categorical variables and the complex sample general linear model for continuous variables. Complex sample logistic regression analysis was performed to examine the relationship between urinary incontinence and impaired bone health of the total femur, femoral neck, and lumbar spine. Potential covariates included age, height, weight, smoking status, alcohol consumption, frequency of exercise, physical activity restriction, 25- $\mathrm{OH}$ vitamin $\mathrm{D}$, amount of calcium consumption, underlying disease, and hormone therapy. The group without urinary incontinence was used as the reference group. Odds ratio (OR) and $95 \%$ confidence interval $(95 \% \mathrm{Cl})$ were calculated.

All the analyses were weighted to incorporate sampling weight, considering the multistage probability sampling design of KNHANES, and response rate, which made the results representative of the entire population of older women. Weight values were determined using the number of participants in the research year and the research items examined. Results with $p$ values of $<0.05$ were considered significant. Data management and analysis were performed using the SPSS ver. 20.0 software (IBM Corp., Armonk, NY, USA).

\section{RESULTS}

\section{General Characteristics of the Participants}

In this representative population, 9.5\% of the Korean women aged $>65$ years had urinary incontinence. On the other hand, only $3.0 \%$ of the participants were diagnosed by a physician. No statistically significant differences in age, height, and weight were found between the two groups regardless of incontinence incidence. Furthermore, underlying diseases such as hypertension, diabetes, and depression showed no significant differences between the two groups. Physical activity restriction due to accident, disease, and sensory impairment (decreased visual acuity, hearing impairment, and tooth condition) was higher in the no urinary incontinence group than in the urinary continence group $(p=0.034)$. Statistically significantly less subjects in the incontinence group received hormone replacement therapy $(p=0.015)$. The characteristics of the study participants are presented in Table 1.

\section{Bone Health and Urinary Incontinence}

Table 2 shows the BMDs and T-scores adjusted for age, height, and weight difference between the urinary continence and no urinary continence groups. The adjusted T-score for the lumbar spine was $-2.48 \pm 0.11$ for the urinary incontinence 
Table 2: Bone mineral density and T-score according to urinary incontinence status

\begin{tabular}{llll}
\hline & No Urinary incontinence & Urinary incontinence & \\
\hline Bone mineral density $\mathbf{( g / \mathbf { c m } ^ { 2 } )}$ & & & $\boldsymbol{P}$ \\
\hline Total femur & $0.70 \pm 0.00$ & $0.68 \pm 0.01$ & 0.376 \\
\hline Femoral neck & $0.55 \pm 0.00$ & $0.54 \pm 0.01$ & 0.739 \\
\hline Lumbar spine & $0.73 \pm 0.00$ & $0.72 \pm 0.01$ & 0.390 \\
\hline T score & & & \\
\hline Total femur & $-1.32 \pm 0.03$ & $-1.43 \pm 0.12$ & 0.399 \\
\hline Femoral neck & $-2.41 \pm 0.02$ & $-2.44 \pm 0.11$ & 0.739 \\
\hline Lumbar spine & $-2.37 \pm 0.03$ & $-2.48 \pm 0.11$ & 0.390 \\
\hline
\end{tabular}

Adjusted by age, height and weight.

Values are expressed as mean \pm standard error.

Calculated by complex sample general linear model

Table 3: Multivariate analysis of urinary incontinence and impaired bone health

\begin{tabular}{lcccc}
\hline & Multivariated OR & Multivariated OR & & Multivariated OR $^{\mathbf{b}}$ \\
\hline Total femur & & & & \\
\hline No UI & 1 & 1 & 1 & 1 \\
\hline UI & $1.23(0.71-2.14)$ & $1.11(0.30-4.11)$ & $1.33(0.72-2.46)$ & $1.36(0.72-2.55)$ \\
\hline Femoral neck & 1 & 1 & 1 & 1 \\
\hline No UI & $1.48(0.52-4.21)$ & $1.63(0.55-4.87)$ & $1.66(0.54-5.09)$ & $1.56(0.53-4.61)$ \\
\hline UI & 1 & 1 & & 1 \\
\hline Lumbar spine & $1.78(0.71-4.47)$ & $1.94(0.76-4.92)$ & $1.85(0.71-4.82)$ & $1.72(0.66-4.48)$ \\
\hline No UI & & & &
\end{tabular}

Urinary incontinence: UI

Impaired bone health included ostepenia and osteoporosis.

Values are expressed as odds ratio (95\% confidence interval).

${ }^{a}$ Adjusted by age, height and weight.

${ }^{\mathrm{b} A d j u s t e d ~ b y ~ a g e, ~ h e i g h t, ~ w e i g h t, ~ s m o k i n g ~ s t a t u s, ~ a l c o h o l ~ c o n s u m p t i o n, ~ f r e q u e n c y ~ o f ~ e x e r c i s e, ~ a n d ~ p h y s i c a l ~ a c t i v i t y ~ r e s t r i c t i o n . ~}$

'Adjusted by age, height, weight, smoking status, alcohol consumption, frequency of exercise, physical activity restriction, 25-OH vitamin D, and amount of calcium consumption.

${ }^{\mathrm{d}}$ Adjusted by age, height, weight, smoking status, alcohol consumption, frequency of exercise, physical activity restriction, 25-OH vitamin $\mathrm{D}$, amount of calcium consumption, underlying disease, and hormone therapy

group and $-2.37 \pm 0.03$ for the no urinary continence group $(p=0.390)$. Furthermore, T-scores for the total femur $(-1.43$ \pm 0.12 vs $-1.32 \pm 0.03)$ and femoral neck $(-2.44 \pm 0.11$ vs $-2.41 \pm 0.02)$ were not statistically significant $(p=0.399$ and $p=0.739$, respectively).

We examined the adjusted ORs for impaired bone health of the total femur, femoral neck, and lumbar spine in the two groups. Table 3 shows the results. After adjusting for age, height, and weight, the ORs $(95 \% \mathrm{Cl})$ for impaired bone health of the total femur, femoral neck, and lumbar spine were $1.23(0.71-2.14), 1.48(0.52-4.21)$, and $1.78(0.71-4.47)$, respectively. Similarly, we found no statistically significance when we adjusted for age, height, weight, smoking status, alcohol consumption, frequency of exercise, physical activity restriction, 25-OH vitamin, amount of calcium consumption, underlying disease (hypertension, diabetes, and depression), and hormone therapy, which showed significant differences between the no urinary continence and urinary incontinence groups in the univariate analysis. Urinary incontinence is not an independent risk factor of impaired bone health.

\section{DISCUSSION}

This study has important meaning because it is the first domestic study of the association between urinary incontinence and bone health that used KNHANES data. In this representative population-based study, we showed that $9.5 \%$ of the elderly women reported inconvenience due to urinary incontinence and only $3.0 \%$ were diagnosed as having urinary incontinence by a physician. BMD and T-score for the total femur, femoral neck, and lumbar spine were lower in the urinary incontinence group than in the no urinary continence group, although this has no statistical significance. Urinary incontinence was not associated with the increased risk of impaired bone health in the Korean elderly women in this study.

Aging lowers the reserve capacity of homeostasis. Thus, organ function deteriorates, and the presentation of the disease is atypical because of concurrent multiple pathologies, multimorbidity, and polypharmacy due to various risk 
factors and chronic diseases (15). Symptoms and signs manifest as geriatric syndrome. Many of the most common conditions in the elderly, including delirium, falls, frailty, osteoporosis, dizziness, syncope, and urinary incontinence, are classified as geriatric syndromes. A distinctive feature of geriatric syndrome is that shared risk factors of distinct geriatric syndrome simultaneously occur with two or more chronic diseases (multi-morbidity) (16). Multimorbidity affects the functioning of the elderly, hospitalization rate, hospitalization period, readmission rate, and mortality rate (17).

In this study, subjects who received hormone therapy were less likely to experience urinary incontinence. Prolonged estrogen deficiency are known to be closely linked to urogenital problems, including frequency, nocturia, and urinary incontinence (18). Estrogen deficiency leads to atrophy of the urethral mucosa, reduction in urethral closure pressure, and changes associated with urinary incontinence (19). Furthermore, hypoestrogenism in elderly and young women, which is related to pathological background, is associated with decreased BMD (20). Decreased estrogen levels are important shared risk factor of urinary incontinence and impaired bone health in elderly women (21). Elderly care requires understanding of multimorbidity and a comprehensive approach.

The prevalence of urinary incontinence widely varied according to the study method and subjects. In previous studies in Western populations, $19.3 \%$ of women aged $>60$ years had urinary incontinence (22), and the prevalence of urinary incontinence among women aged $>40$ years was 53.7\% (23). On the other hand, in this study, among the 901 women, only $9.5 \%$ reported having a urinary incontinence problem. In general, many Korean elderly women regard urinary incontinence as a natural consequence of aging. They tend to think urinary incontinence as natural and not an illness. Furthermore, because of shame, many elderly women tend to conceal their problem. However, the prevalence of urinary incontinence in this report was different from that in a previous study in Korea (24). We randomly sampled 500 Korean women and included them in the study. The survey comprised a computer-aided telephone interview and consisted 16 questions about urinary incontinence. Among the responders, 23.8\% of the women had urinary incontinence and $28.9 \%$ aged $>60$ years $(n=80)$ experienced urinary incontinence in the past 6 months. In this study, we used data from the KNHANES, a nationwide survey, so our study has a strength in that reflect the health status of the entire Korean population. However, the KNHANES assessed urinary incontinence on the basis of only one simple question in the selfreported questionnaire, thereby limiting the assessment of the actual prevalence of urinary incontinence.

This study has several limitations. First, in this study, we could not distinguish the subtypes of urinary incontinence. In aging, the prevalence of urge incontinence is increased, and mixed incontinence was more prevalent than stress urinary incontinence (25). Stress incontinence mainly due to the weakening of the pelvic floor muscles, including the pubococcygeal, levator ani, and sphincter muscles; unlike stress incontinence, urge incontinence is mainly caused by bladder dysfunction (26). Urinary incontinence of various mechanisms is difficult to distinguish, and the pure effect of the muscle weakness in urinary incontinence on impaired bone health is difficult to evaluate. Not only assessment of the type of urinary incontinence but also evaluation of symptom severity by using questionnaires such as the Incontinence Quality of Life (I-QoL) Instrument and King's Health Questionnaire (KHQ) is meaningful but could not be done in our study $(27,28)$. We controlled various factors that influence urinary incontinence and osteoporosis. However, we could not assess eating pattern, amount of total calorie, and protein intake. It is our second limitation. In this study, calcium and $25-\mathrm{OH}$ vitamin D levels, which play important roles in bone health, were evaluated. Both groups were below the appropriate intake of calcium and showed levels lower than the reference value. Furthermore, parity and menopausal age are both important factors of urinary incontinence and bone health, but in this study, we could not evaluate these variances. Considering the current knowledge regarding this problem, we would like to conduct a study that complements the limitations of our present research.

In conclusion, urinary incontinence was not an independent risk factor of impaired bone health in the elderly women in this study.

\section{ACKNOWLEDGEMENTS}

This work was supported by a research grant from Jeju National University Hospital in 2017. 


\section{REFERENCES}

1. Abrams $\mathrm{P}$, Cardazo L, Fall M, et al. The standardisation of terminology in lower urinary tract function: report from the standardisation subcommittee of the International Continence Society. Urology. 2003;61(1):37-49. https://doi.org/10.1016/S0090-4295(02)02243-4

2. Kwon CS, Lee JH. Prevalence, risk factors, quality of life, and health-care seeking behaviors of female urinary incontinence: results from the 4th Korean National Health and Nutrition Examination Survey VI (2007-2009). Int Neurourol J. 2014;18:31-6. https://doi.org/10.5213/inj.2014.18.1.31 PMid:24729925 PMCid:PMC3983507

3. Price N, Dawood R, Jackson SR. Pelvic floor exercise for urinary incontinence: a systematic literature review. Maturitas. 2010;67:309-15. https://doi.org/10.1016/j.maturitas.2010.08.004 PMid:20828949

4. Stav K, Alcalay M, Peleg S, Lindner A, Gayer G, Hershkovitz I. Pelvis architecture and urinary incontinence in women. Eur Urol. 2007;52:239-44. https://doi.org/10.1016/j.eururo.2006.12.026 PMid:17207915

5. Park YW, Lee JH. Female urinary incontinence and obesity assessed by anthropometry and dual-energy $\mathrm{X}$-ray absorptiometry: analysis from the 2008-09 Korean National Health and Nutrition Examination Survey. Low Urin Tract Symptoms. 2017. https://doi.org/10.1111/luts.12207 PMid:29119694

6. Cruz-Jentoft AJ, Baeyens JP, Bauer JM, Boirie Y, Cederholm T, Landi F, Martin FC, Michel JP, Rolland Y, Schneider SM, Topinková E, Vandewoude M, Zamboni M; European Working Group on Sarcopenia in Older People. Sarcopenia: European consensus on definition and diagnosis: report of the European Working Group on Sarcopenia in older people. Age Ageing. 2010;39:412-23. https://doi.org/10.1093/ageing/afq034 PMid:20392703 PMCid:PMC2886201

7. Kim TN. Diverse abnormal body composition phenotypes: interaction between muscle, fat, and bone. Korean J Obes. 2015;24:9-16. https://doi.org/10.7570/kjo.2015.24.1.9

8. Lima RM, Bezerra LM, Rabelo HT, Silva MA, Silva AJ, Bottaro M, de Oliveira RJ. Fat-free mass, strength, and sarcopenia are related to bone mineral density in older women. J Clin Densitom. 2009;12:35-41. https://doi.org/10.1016/j.jocd.2008.10.003 PMid:19084449

9. Hamrick MW. The skeletal muscle secretome: an emerging player in muscle-bone crosstalk. Bonekey Rep. 2012;1:60. https://doi.org/10.1038/bonekey.2012.60 PMid:23951457 PMCid:PMC3727847

10. Hamrick MW, McNeil PL, Patterson SL. Role of muscle-derived growth factors in bone formation. J Musculoskelet Neuronal Interact. 2010;10:64-70.

11. Hamrick MW. A role for myokines in muscle-bone interactions. Exerc Sport Sci Rev. 2011;39:43-7. https://doi.org/10.1097/JES.0b013e318201f601 PMid:21088601 PMCid:PMC3791922

12. Nygaard I, Girts T, Fultz NH, Kinchen K, Pohl G, Sternfeld B. Is urinary incontinence a barrier to exercise in women? Obstet Gynecol. 2005;106:307-14. https://doi.org/10.1097/01.AOG.0000168455.39156.0f PMid:16055580

13. Smith MD, Coppieters MW, Hodges PW. Is balance different in women with and without stress urinary incontinence? Neurourol Urodyn. 2008;27:71-8. https://doi.org/10.1002/nau.20476 PMid:17623853

14. Brown JS, Vittinghoff E, Wyman JF, Stone KL, Nevitt MC, Ensrud KE, Grady D. Urinary incontinence: does it increase risk for falls and fractures? Study of the Osteoporotic Fractures Research Group. J Am Geriatr Soc. 2000;48:7215. https://doi.org/10.1111/j.1532-5415.2000.tb04744.x PMid:10894308

15. Yoo HJ. What is geriatric disease? J Korean Geriatr Soc. 2008;12:61-7.

16. Inouye SK, Studenski S, Tinetti ME, Kuchel GA. Geriatric syndromes: clinical, research, and policy implications of a core geriatric concept. J Am Geriatr Soc. 2007;55:780-91. https://doi.org/10.1111/j.1532-5415.2007.01156.x PMid:17493201 PMCid:PMC2409147

17. Fuchs Z, Blumstein T, Novikov I, Walter-Ginzburg A, Lyanders M, Gindin J, Habot B, Modan B. Morbidity, comorbidity, and their association with disability among community-dwelling oldest-old in Israel. J Gerontol A Biol Sci Med Sci. 1998;53:M447-55. https://doi.org/10.1093/gerona/53A.6.M447

18. Schaffer J, Fantl JA. Urogenital effects of the menopause. Baillieres Clin Obstet Gynaecol. 1996;10:401-17. https://doi.org/10.1016/S0950-3552(96)80022-8

19. Hextall A, Cardozo L. The role of estrogen supplementation in lower urinary tract dysfunction. Int Urogynecol J Pelvic Floor Dysfunct. 2001;12:258-61. https://doi.org/10.1007/s001920170049 PMid:11569655

20. Męczekalski B, Podfigurna-Stopa A, Czyżyk A, Katulski K, Maciejewska-Jeske M. Why hypoestrogenism in young women is so important. Arch Perinat Med. 2014;20:78-80. 
21. Ozbek E, Dursun M, Otunctemur A, Sami Cakir S, Can Polat E. Stress urinary incontinence in premenopausal and postmenopausal women: evaluation of serum estradiol levels and bone mineral density. Minerva Ginecol. 2014;66:293-8.

22. Irwin DE, Milsom I, Hunskaar S, Reilly K, Kopp Z, Herschorn S, Coyne K, Kelleher C, Hampel C, Artibani W, Abrams P. Population-based survey of urinary incontinence, overactive bladder, and other lower urinary tract symptoms in five countries: results of the EPIC study. Eur Urol. 2006;50:1306-14. https://doi.org/10.1016/j.eururo.2006.09.019 PMid:17049716

23. Ueda T, Tamaki M, Kageyama S, Yoshimura N, Yoshida O. Urinary incontinence among community-dwelling people aged 40 years or older in Japan: prevalence, risk factors, knowledge and self-perception. Int J Urol. 2000;7:95-103. https://doi.org/10.1046/j.1442-2042.2000.00147.x PMid:10750888

24. Choi H, Park JY, Yeo JK, Oh MM, Moon DG, Lee JG, Bae JH. Population-based survey on disease insight, quality of life, and health-seeking behavior associated with female urinary incontinence. Int Neurourol J. 2015;19:39-46. https://doi.org/10.5213/inj.2015.19.1.39 PMid:25833480 PMCid:PMC4386485

25. Diokno AC, Brock BM, Brown MB, Herzog AR. Prevalence of urinary incontinence and other urological symptoms in the noninstitutionalized elderly. J Urol. 1986;136:1022-5. https://doi.org/10.1016/S0022-5347(17)45194-9

26. Choi JB. Urinary incontinence in women. Korean J Fam Med. 2010;31:661-71. https://doi.org/10.4082/kjfm.2010.31.9.661

27. Oh SJ, Park HG, Lim SH, Hong SK, Martin ML, Ting BL, Kim SW, Kim HH, Paick JS. Translation and linguistic validation of Korean version of the Incontinence Quality of Life (I-QoL) Instrument. J Korean Continence Soc. 2002;6:10-23. https://doi.org/10.5213/jkcs.2002.6.2.10

28. Oh SJ, Choo MS, Kim HS, Kim JC, Lee JG, Yun JM, Kim DY, Paick JS, Lee JY, Chung BS, Min KS, Kim YH, Jung HC, Son $\mathrm{H}$, Jeong JY, Rho J, Lee KS, Kang W, Park WH. Psychometric properties of the Korean version of the King's health questionnaire in women with stress urinary incontinence. J Korean Continence Soc. 2005;9:115-23. https://doi.org/10.5213/jkcs.2005.9.2.115

$\diamond \diamond \diamond \diamond \diamond \diamond \diamond$

http://www.ejgm.co.uk 